\title{
ABSTRACTS
}

\section{NOSE AND ACCESSORY SINUSES.}

Surgical Diathermy in the Treatment of Synechiae. W. STUPKA, Innsbruck. (Zeitschrift für Hals-, Nasen-, und Ohrenheilk, Vol. xi., Part I, March 1925.)

The writer gives detailed reports of several troublesome cases in which this method of treatment seemed to have been effective. In one case purulent dacryo-cystitis was present, and it was only after removing a mass of cicatricial tissue (of hereditary luetic origin) by means of diathermy that it was possible to perform the intranasal operation on the lacrymal sac. James Dundas-Grant.

Melanotic Sarcoma of the Septum Nasi. Philip R. W. DE Santi, F.R.C.S. (Brit. Med. Journ., I 7 th January 1925.)

The case recorded was seen first as a purple tumour on the anterior part of the septum, subject to frequent bleeding. Microscopic examination showed it to be a melanotic sarcoma. The tumour was removed and the base scraped, radium being subsequently applied.

Six months later recurrence took place and lateral rhinotomy was performed and the tumour was removed en masse. There was then no extension to the naso-pharynx or antrum, nor any demonstrable secondary deposits. After some months recurrence again took place and radium was used on several occasions, but without benefit. The antrum was now involved, and a further operation by lateral rhinotomy combined with diathermy was performed. This brings the case up to quite a recent date.

The extreme rarity of the condition is referred to, and the author advocates the use of radium in sarcomatous tumours of the nose, while expressing the view that carcinomata, on the other hand, are rather stimulated by this form of treatment.

T. Ritchie Rodger.

Nasal Complaints caused by an Alveolar Sequestrum. George Bjorkquist, Helsingfors. (Acta Oto-Laryngologica, Vol. vi., fasc. 3-4.)

The case is recorded of a patient who complained of nasal obstruction and increasing deafness.

Eleven and a half years previously he had received a kick on the mouth, with loosening of the front teeth of the upper jaw. Two main portions of dead bone had been removed from the front part of the floor of the nose, that on the left side extending from a perforation in the septum to a perforation of the inner antral wall.

6 ro 


\section{The Nose and Accessory Sinuses}

Free nasal breathing with cessation of discharge and odour have resulted, and the hearing, aided by catheterisation treatment, is improved.

The etiology can be definitely traced to the blow eleven and a half years ago.

\section{H. V. FORSTER.}

\section{Goundou. J. N. Roy. (Archives Internationales de Laryngologie, March 1925.)}

Goundou is a tropical disease which is endemic amongst the natives of West Africa. It is characterised by the formation of a bony swelling localised to the para-nasal region of one or both sides. The disease may be associated with exostoses in any other bone of the body.

Goundou is chiefly found in males and first makes its appearance in the very young; occasionally, however, it starts in adult life.

The bibliography appended shows that the disease has been most extensively studied by British investigators.

The origin of goundou is unknown. There appears to be some connection between it and the skin disease framboesia. The author is in agreement with the majority of observers in regarding the nature of the disease as inflammatory, a chronic osteitis.

The symptoms and physical signs are those of deformity and the result of pressure on neighbouring structures. The orbit is sometimes so severely encroached upon that the eyeball is completely dislocated.

The author gives a brief analysis of 34 cases.

Goundou is not improved by any known medical treatment. Anti-syphilitic treatment has no effect on the disease, and the author believes that there is no relation between the two conditions.

The author has treated several cases by excising the osseous growths. There has been no recurrence.

Michael Vlasto.

\section{Psycho-Galvanic Reflex Phenomenon in Sense Organs, especially the Nose. J. Bijtel, Amsterdam; C. G. A. Van Iterson, Leyden. (Acta Oto-Laryngologica, Vol. vii., fasc. I.)}

One of the authors having made experiments concerning the psycho-galvanic reflex following sound stimulus (Acta Oto-Laryngologica, Vol. ii., 1920), it was decided to investigate whether certain odours produced a similar reflex. A special apparatus was made and a string galvanometer used as a recorder. Stimuli from changes of light and sound were carefully eliminated. Positive results were obtained with a latent period of two seconds, but the deviation of the galvanometer did not vary appreciably for odours of different kinds.

H. V. FORSTER.

$6 \mathrm{II}$ 


\begin{abstract}
s
Sinusitis as a Source of Disease, and its Effective Treatment. Sydney PERn. (Medical Journal of Australia, 9th May r925.)
\end{abstract}

After recording his experience in the treatment of various diseases due to focal infection, and setting out the same in a series of seven tables, Pern proceeds : "Having in the past experienced unsatisfactory results in my patients from operative treatment, and having also found the use of vaccines unavailing, I looked for some other method in the hope of benefiting these patients.

"As I was using colloidal manganese about this time for other conditions, I tried it in some cases of sinusitis with quite remarkable results. I found it almost a specific, and that it usually cleared up the condition in a fortnight or three weeks, and that four to eight injections were generally sufficient to produce a cure.

"Since then, I have employed it in some hundreds of cases with consistent result. It cures not only the focal infection, but also the diseased condition which results from the infection."

A. J. Brady.

\title{
An Unusual Case of Displacement of the Eyeball due to a Myxoma of the Frontal Sinus. G. KLIONSKy. (Lancet, I925, Vol. i., p. 126.)
}

The case was that of a married woman of 6o. Diplopia for three months; no other history. Displacement of right eye, noticed for two weeks, forwards, downwards, and outwards. Fundus normal; no pulsation; nasal and X-ray examination indefinite. While in hospital, she had an attack of acute glaucoma. Operation showed the frontal sinus to be occupied by a large growth, presumed from its macroscopic appearances to be a myxoma ; unfortunately no microscopic examination was obtained.

Macleod Yearsley.

Present Status of Intranasal Ethmoid Operation. John A. PratT. (Archives of Oto-Laryngology, 1925, Vol. i.)

Questionnaires were sent to 165 leading rhinologists in the United States regarding deaths following intranasal ethmoid operations, and information requested as to whether or not all or part of the middle turbinate had been removed. Eighty deaths were reported, and in seventy-eight of these cases, all or part of the middle turbinate had been removed. Pratt therefore concludes that the perineural spaces about the olfactory nerve are opened up, and may serve as a direct path for meningeal infection. Infection from injury to the cribriform plate is rarer. The middle turbinate or medial wall of the ethmoid should therefore only be removed in exceptional cases.

T. W. M'CART.

612 


\title{
Peroral Endoscopy
}

\author{
Empyema of the Left Sphenoidal Sinus, with Optic Neuritis and \\ subsequent Post-papillitic Atrophy. R. E. WRIGHT, M.D., Major \\ I.M.S. (Brit. Med. Journ., 28th March 1925.)
}

In this case, although the right eye was almost blind from optic atrophy, while the left showed only slight neuritis with little loss of vision, the left sphenoidal sinus was the one containing pus. "Presumably both optic nerves were related to this sinus, the right nerve being more vulnerable (either by virtue of a longer course in the sinus or a thinner bony canal) than the left."

To aid the interpretation of the X-ray plates the device was adopted of packing the sphenoidal sinus with bismuth gauze and then taking a stereoscopic photograph.

T. Ritchie Rodger.

\section{PERORAL ENDOSCOPY.}

Congenital Esophageal Stenosis due to Membranous Constriction and to CEsophagectasis. A. SARGNON. (Archives Internationales de Laryngologie, 1925.)

The author deals only with those forms of congenital stenosis of the oesophagus which are compatible with life.

His remarks are based on two cases of membranous constriction, and on one of infantile cesophagectasis.

The first case of membranous constriction occurred in a child of ten and a half years, who had suffered from regurgitation since the age of three and a half months. A number 30 bougie was arrested at 27 to $28 \mathrm{~cm}$. from the teeth. The position of the constriction was confirmed by osophagoscopy. Radioscopy showed a stenosis of the cardiac orifice of the stomach.

The patient was cured after several weeks of methodical dilatation.

The second case was a child aged 4 years, who had been vomiting intermittently since infancy. Liquid nourishment could alone be retained. X-rays showed that there was a constriction 6 to $7 \mathrm{~cm}$. above the diaphragm with secondary dilatation higher up. Esophagoscopy revealed a membranous constriction with a tiny perforation in the centre which barely allowed the passage of a number 14 bougie. Dilatation was carried out every two days and the bougie was left in a little longer every day. The patient was seen again four months after he first came under observation and a number 14 bougie was passed with ease.

The case of congenital œsophagectasis occurred in a child aged twelve and a half years, who was admitted with vomiting and starvation. The symptoms appear to have been first noted at the age of II. Radioscopy showed a very dilated cesophagus with a kink in the diphragmatic region. A bismuth meal could not pass into the stomach. 


\section{Abstracts}

A number 25 bougie was arrested at $3^{6} \mathrm{~cm}$. from the upper teeth. Dilatation was carried out over a period of several months with great improvement.

A short account of the literature on the subject is given.

The author concludes with the statement that the rare condition of congenital œesophageal stenosis is curable by relatively simply measures. Michel Vlasto.

Cicatricial Stenosis of the Esophagus, with particular reference to Treatment by continuous String Retrograde Bouginage with the Author's Bougie. Gabriel Tucker, M.D. (Annals of Otology, Rhinology, and Laryngology, December 1924, Vol. xxxiii., p. 1180 .)

After condemning blind bougieing as unsafe, uncertain and obsolete, the author describes his new method of treatment of retrograde string bouginage.

A gastrostomy is first performed, thus placing the osophagus at rest and enabling the patient to be substantially nourished. As a result the œsophagitis around the strictures, which he points out are frequently multiple, rapidly improves and the stricture usually opens sufficiently to allow the swallowing of a string. Stringing the œesophagus is the next procedure. Tucker points out that this "may require several weeks' persistent effort." At the Bronchoscopic clinic No. I 5 button-hole twist silk is first used. Various methods of encouraging the string to pass the stricture have been tried, such as floating the string on swallowed water or attaching small perforated shot to one end. The author has found that the unknotted slightly frayed end more readily engages into and passes the stricture. In small children, to prevent biting of the string, it may be passed through the nose with a Bellocq's sound or a small rubber catheter. The end of the string is wrapped round a piece of adhesive plaster used as a bobbin and the intervening portion of string is carried round the cheek and over the ear.

The bobbin is fastened at the back of the neck, and it and the string are covered with adhesive plaster so as to prevent the child pulling the string out. At intervals of a few hours more string is unwound and given the patient to swallow or is passed along the nose. As soon as it is judged that sufficient string has passed into the stomach a small right-angled retractor is passed through the gastrostomy opening and the string searched for and withdrawn. The fine string is now usually replaced by No. 4 Persal twisted silk.

If the string cannot be swallowed a bougie may be passed up into the mouth with the aid of a retrograde œsophagoscope; the string is then tied to the end of the bougie presenting in the mouth and withdrawn through and out of the stomach; or, by simultaneous retrograde 


\section{Peroral Endoscopy}

and peroral œesophagoscopy two operators may pass a bougie through a resistant stricture and so string the cesophagus. Tucker uses a bougie made of the best quality of rubber, moulded on an endless braided silk thread. A loop is left free at either end and the intervening portion is knotted so as to prevent pulling out of the rubber. The ends are tapered and the sizes vary from ten to thirty French scale. The length of the rubber portion of the bougie is $35 \mathrm{~cm}$.

During treatment the loop of string is worn over the ear and the child can attend school. When passing the bougie the patient is dorsally recumbent, the feeding-tube removed, and the string divided in the middle of the loop.

A new string is attached close to the gastrostomy opening and to the lower end of the old string is attached the bougie. Upward traction of the string is gently made whilst using the index finger of one hand, placed behind the back of the tongue, as a pulley. The bougie is retained in the stricture for fifteen to thirty minutes, and Tucker points out that patients are more tolerant to retrograde methods than the more usual peroral method of bouginage. Only very gradual stepping up in the size of the bougie is adopted, and the treatment is carried out once or twice weekly according to the amount of reaction produced.

Tucker records a series of twenty-five cases so treated, and considers that although preliminary œesophagoscopy is always advisable to determine the condition of the cesophagus before beginning treatment, once the string is in place no further examination is necessary.

\section{F. Holt Diggle.}

A Clinical Study of Primary Dilatation of the Esophagus. A. SARGNon. (L'Oto-Rhino-Laryngologie Internationales, August I924.)

The first case occurred in a young woman. Esophagoscopy during life showed extreme dilatation but no stenosis; in addition, signs of enlarged mediastinal glands were present. The patient committed suicide, and the post-mortem showed the following changes: Degeneration, sclerosis and hypertrophy of the external muscular coat, i.e., a condition in which no stenosis was present but in which the changes in the csophageal wall were most marked at the periphery, suggesting that the trouble had progressed from without inwards.

In the second case, the patient was under observation with œsophageal dilatation for fifteen years. During the earlier period catheterisation was easy; latterly it became more difficult and finally impossible. Radiography now shows enormous elongation of the œsophagus which is curled into an $\mathrm{S}$, explaining the impossibility of 


\section{Abstracts}

catheterisation. This case emphasises particularly the factor of a pathological curvature in the dilated œsophagus. The third case was a child of 12 years, who had had some difficulty in swallowing since one year old. Radiography and cesophagoscopy showed extensive dilatation. Catheterisation was easy.

\section{General Conclusions founded on these Cases.}

Etiology-Age is important. The condition may occur in infancy. Some cases of so-called idiopathic dilatation are really secondary to some other lesion, as in the first case.

Pathology-Elongation is an important factor. The most striking characteristic is the fact that there is no stenosis in the cardiodiaphragmatic region.

A general review of theories as to the etiology, diagnosis, and treatment is also given. A. J. Wright.

\section{Rare Forms of Fsophageal Cancer. J. Guisez, Paris. (Bulletin d'Oto-Rhino-Laryngologie, Paris, January 1925.)}

Secondary cancer of the cesophagus is rare. By direct extension, it is not uncommon for œsophageal cancer to give rise to secondary deposits in other parts, but the converse process is seldom seen. Two cases of tracheal cancer which gave rise to œsophageal lesions, and one of the left bronchus similarly involving the œesophagus, are reported; dyspnœa had preceded dysphagia; hence it had been assumed that the osophageal lesions were secondary. Two further cases in which laryngeal cancer involved the œsophagus are given. Finally, four cases of a different kind are cited; in one, cancer of the cheek, and in three, cancer of the breast, gave rise to secondary deposits in the œsophagus.

Multiple cancers of the oesophagus may occur.

(r) Male, aged 54. Malignant polypus of the upper third of the œesophagus and cauliflower cancer of the lower third.

(2) Female. Post-cricoid cancer, and another $15 \mathrm{~cm}$. farther down the cesophagus.

(3) An epithelioma at $17 \mathrm{~cm}$. from the teeth was treated by radium, with relief; four months later, another was found $33 \mathrm{~cm}$. down the œsophagus, and treatment of the latter likewise with radium resulted in relief for over a year.

(4) Male, aged 56. Post-cricoid carcinoma treated with radium. Six months later, the original site was healthy, but a cancer was found $34 \mathrm{~cm}$. from the teeth.

(5) Female, aged 66 . Cauliflower tumour $30 \mathrm{~cm}$. from the teeth treated with radium. Three years later, a cancer was found $23 \mathrm{~cm}$. from the teeth, the previously affected part was apparently normal.

E. WatSON-WILLiams.

$$
616
$$




\section{Peroral Endoscopy}

Sarcoma of the Esophagus. HenRy B. ORTON, M.D. (Annals of Otology, Rhinology, and Laryngology, December 1924, Vol. xxxiii., p. 1236.$)$

Orton bases his summary on 46 cases collected by Bertholet, in I 9 I I, to which he adds 5 , one being under his own care.

From the collected cases it appears that sarcoma of the osophagus occurs late in life, usually between the ages of 40 to 70 years, though it may be evident as young as 4 years or as old as 80 years. Age, therefore, cannot be considered as of any diagnostic value. Males have been more commonly the sufferers, in the proportion of 3 to 1 .

The first symptom noticed is sudden onset of dysphagia usually experienced with solid foods. Pain is a dominating symptom and occurred in all the cases in a varying character. The pain is more usually referred to the thorax, though it may occur in the throat, neck, head, shoulders, arms, and fingers. All pain was increased on swallowing. Dysphagia was always noticed.

Of the recorded cases, I 8 were classified as simply sarcoma, 14 as spindle sarcoma, 4 lympho-sarcoma, 4 round-celled sarcoma, 2 fibrosarcoma, 2 myeloid sarcoma, 2 melanotic sarcoma, and 5 as unclassified. In females the growth was more commonly situated at the middle third or above, most of them being at the cricoid, whilst in males the lower two-thirds of the œsophagus were usually affected.

Metastatic growths were noticed in 18 cases. Pain is almost of diagnostic value, though it is impossible to differentiate the condition from carcinoma without the aid of œsophagoscopy.

Orton considers it important to exclude malignancy in any œsophageal polyp, as both carcinoma and sarcoma may present themselves as genuine polypi. Radium and deep X-ray therapy appear to be the only means of relieving the pain and slightly prolonging life.

\section{F. Holt Diggle.}

\section{Durable Results after Radium Treatment of Osophageal Cancer. J. GuIsez, Paris. (Bulletin d'Oto-Rhino-Laryngologie, Paris, July 1924.)}

Dr Guisez reports 20 cases in which malignant stricture of the œsophagus has been relieved for several years following the application of radium; in all, the diagnosis was confirmed by microscope. Of these, 2 survived thirteen years, I ten years, 8 from two to four years, and 9 less than two years; only $\mathrm{I}$ had a recurrence. $\mathrm{He}$ points out that œesophageal cancer is specially amenable to radium. It is of slow growth, and distant metastases are rare. A basal cell carcinoma is the usual type. Diagnosis can be made with practical certainty by the macroscopic appearance. Syphilis is a pathological curiosity; no other condition occurs which could cause confusion. Microscopic verification is always possible. 


\section{Abstracts}

For treatment on the lines advised it is necessary-

1. That the exact position and length of the stricture be known.

2. That the condition of the patient be not actually desperate.

3. That a sufficient lumen remains for the introduction of the radium tube; this is usual.

Dr Guisez uses the "tubes of Dominici" fixed end to end in the soft rubber esophageal tube. The short radium holders, attached to a thread, are absolutely rejected; they are difficult to arrange to cover the whole length of the growth, and seldom remain in place. After introduction, the loaded tube is fixed at the necessary depth, so that the entire length of the growth is irradiated. This tube is well borne. At least $12 \mathrm{cgm}$. of radium bromide are used, screened by $1.5 \mathrm{~mm}$. of platinum. Each application is for twelve to twenty hours, and they are repeated on alternate days till a total exposure of ninety-six hours has been given. Apart from the cases related, only palliative results have been seen. The sufferers from this condition, in fact, come for treatment only at a late stage of the disease. E. Watson-WiLliams.

Esophagoscopy: A Means of Detecting Foreign Bodies non-opaque to X-rays. W. Frank WILson, M.B. (Brit. Med. Journ., 4th April 1925.$)$

Small pledgets of cotton wool are soaked in barium porridge and swallowed one at a time, to the number of six or eight. A minute or so afterwards a teaspoonful or more of barium porridge is swallowed. Two or three minutes are then allowed to elapse to give the surplus barium time to leave the gullet. The gullet is then radiographed, the shadow being generally of the shape of an inverted cone. On passing the osophagoscope, the foreign body is generally found embedded in cotton wool like a chrysalis in its cocoon, but the wool may have to be removed piecemeal in cases of firm impaction. The method would be contra-indicated in the presence of dyspnœa from involvement of the larynx.

T. Ritchie Rodger.

\section{MISCELLANEOUS.}

A Modified Headband for the Zeiss Binocular Lens. A. J. H. M. BAAR, Utrecht. (Acta Oto-Laryngologica, Vol. vii., fasc. i.)

A semi-flexible headband of hard rubber is recommended to carry the rather heavy binocular lens so that it may be worn in comparative comfort and remain quite steady. A mirror with two eye holes is attached as in the Clar forehead lamp. It is suggested that the firm of Zeiss should produce a lens of lighter material and that the eye shells be made smaller so that the operator may look sideways and downwards as well as through the instrument. H. V. Forster. 


\section{Miscellaneous}

Dermoid Cysts of the Floor of the Mouth. RALPH COLP, New York. (Surgery, Gynaecology, and Obstetrics, 1925, Vol. xl., pp. 183-195.)

The author has collected together and studied thirty-two cases of dermoid cysts of the floor of the mouth, not included in the well-known thesis of Debonelle (Les Kystes Dermoides du Plancher de la Bouche, Paris, 1908). In addition, he records two cases of dermoid cyst of the floor of the mouth and one case of lingual cyst from the Mount Sinai Hospital, New York.

Dermoid cysts of the floor of the mouth are rare, and have been confused with ranulæ and sebaceous cysts.

In this contribution the embryonic development of these cysts has been described in detail. The majority were found to be congenital, though many did not develop until late in life-occurring most frequently between the ages of 12 and 25 .

The author divides these tumours, according to their situation, into (a) submental or geniohyoid cysts, situated under the tongue in the region of the frænum, between it and the alveolar margin of the incisor teeth. (b) Sublingual or genioglossal cysts, in the submental region. (c) Lateral cysts, under the horizontal ramus of the lower jaw.

If small they may cause no symptoms, but when larger they elevate the mucous membrane of the floor of the mouth and the tongue by bulging of the tumour upwards, and give rise to alteration in the voice, difficulty in mastication and deglutition, with occasional dyspnœa, due to pressure on the epiglottis. Pain may be present if the lingual nerve is pressed upon.

Exploratory puncture shows sebaceous contents, which indicate either a dermoid or lingual cyst. These can only be differentiated pathologically. Dermoid cysts must also be differentiated from angioma, lipoma, ranula, and carcinoma.

The treatment consists in complete excision of the cyst, either by the buccal or the suprahyoid route, the choice depending upon the size and anatomical character of the cyst. Splitting the lower jaw in the middle line is unnecessary. The difficult cases are those complicated by fistulæ.

A comprehensive bibliography is included with this paper.

IrWIN MOORE.

\section{A Suggestion for the Relief of the Pain from Carcinoma of the Mouth and Cheek. Francis C. Grant. Philadelphia, Pa. (Annals of Surgery, February 1925.)}

In an endeavour to lessen the suffering from growths in these situations, or from the painful dressings after their removal, the author suggests injections of alcohol into the second and third divisions of the 


\section{Abstracts}

fifth nerve, intracranial neurectomy of those divisions or avulsion of the sensory root behind its ganglion. Intracranial neurectomy is preferred. The operation is stated to be simple and more rapid and spares the supraorbital branch. It may be performed under local anæsthesia. No nerve resection, however, will relieve those cases in which there is pain deep in and behind the ear or pain on swallowing.

Of twenty cases of deep injections ten were completely relieved of pain, in seven the pain was greatly lessened, in three there was no benefit. In four of the above cases the maxillary antrum was involved, and in all four pain was relieved. In one case of involvement of the ethmoid and antrum the relief was only partial. In only one out of six cases with involvement of tongue and floor of the mouth was pain relieved. In one of the ten cases where pain was completely relieved an extensive operation was done for removal of growth from jaw and tongue, no other anæsthesia being used. Treatment and dressings are no longer an agony in cases where pain is relieved.

In a series of seven cases major operations were performed, two after intracranial neurectomy, five after avulsion of the sensory root. Four of the seven were pain free afterwards, two were partially relieved, but without relief of pain in the ear and throat.

Nerve blocking in these cases is an act of mercy, ending as it does the sufferings due to the disease and treatment of the affected parts.

Nicol, Rankin.

\section{A Case of Leontiasis Ossea. F. Lemaître, J. Rovget, Ch. Ruppe. (Archives Internationales de Laryngologie, August 1924.)}

A female, aged 47 , seven years before the article was written, developed a swelling of the ascending process of the right superior maxilla, followed soon after by a similar swelling on the left side. Extraction of molar teeth, at a later date, was followed by a saniopurulent discharge and a wound which refused to heal.

Examination of the skull showed thickening in many places. The lower jaw appeared normal. Complete opacity of the antra on transillumination was noted.

Radiography showed the typical woolly appearance of leontiasis ossea.

Surgical interference was carried out and consisted in the extraction of portions of carious bone from the superior maxilla. The maxillary sinuses were found to be filled up with bone formation.

Section of the new bone was made and the microscopical appearance is described. Microphotographs are shown. The most important microscopical characteristic of the disease is the formation of areas of necrosis which become calcified.

Michael Vlasto. 


\section{Miscellaneous}

A Harmonic Electro-Vibrator. E. N. Maljutin, Moscow. (Zeits. fuir Hals-, Nasen-, und Ohrenheilk, Vol. ix., Part 4, p. 429.)

Steel plates vibrating at definite rates to cover the tones and semitones of two octaves can be severally set going by pressure on appropriate contacts which are in circuit with an ordinary telephone receiver. This is placed on the patient's chest, and when he tries to sing the note given by the instrument he finds the emission of the note greatly facilitated. With this instrument can be arranged an electrode for stimulating the larynx simultaneously at the same rate. This is a development of a similar apparatus worked by means of tuning-forks formerly used by the author.

James Dundas-Grant.

\section{Contribution to the Clinical and Radiographic Study of Salivary Calculi. A. SARGNON. (L'Oto-Rhino-Laryngologie Internationale, December 1924.)}

Salivary calculi are uncommon. Only two cases have been observed out of 30,000 patients. Many cases are probably missed. An intermittent swelling of the submaxillary gland, palpable externally and frequently accompanied by pain, is an important and almost constant sign. A skiagram will usually show calculi which are rich in lime salts, but it should be taken with a film in the mouth and the ray entering from below the jaw. If the film be placed externally, the jaw will frequently hide the calculus. An excellent plate is given showing three calculi in Wharton's duct. Removal is best carried out under local anæsthesia, care being taken to avoid leaving fragments of calculus.

A. J. WRIGHT.

\section{Further Statistics on Chlorine Gas as a Treatment for Respiratory Diseases. Jones and Garofalo. (Archives of Oto-Laryngology, Vol. i., r 925. )}

The authors report on 220 cases of acute and chronic diseases of the upper and lower respiratory tract. They found an improvement in acute cases involving the upper respiratory tract, whereas in asthmatic and tuberculous patients the treatment is contra-indicated.

T. W. M'Cart. 